\title{
A Foreword from President Robert S. Nelsen
}

\section{Dear Colleagues,}

The Journal of Transformative Leadership and Policy Studies (JTLPS) is a peer-reviewed journal sponsored by the California State University system and the Doctorate in Educational Leadership at California State University, Sacramento. As the incoming President of California State University, Sacramento, I encourage you to share Volume JTLPS 5.1 with your colleagues and scholarly communities.

The volume's contributions truly advance critical issues impacting education and underscore the importance of critical analysis while tactfully presenting new directions to common educational problems. I find this approach refreshing in a time when we are being challenged to be innovative in our practices. Of particular interest is the essay written by Chancellor White from the California State University system. His candor surrounding leadership, vision, and change provides readers with insights to strategic practices driving the future of the largest fouryear system of higher education in the United States.

The stimulating articles included in this volume point us toward a future that will meet the needs of our students and nation. It provides us with a roadmap to thinking about the role of leadership in changing times.

Fondly,

Robert S. Nelsen, PhD

President

California State University, Sacramento

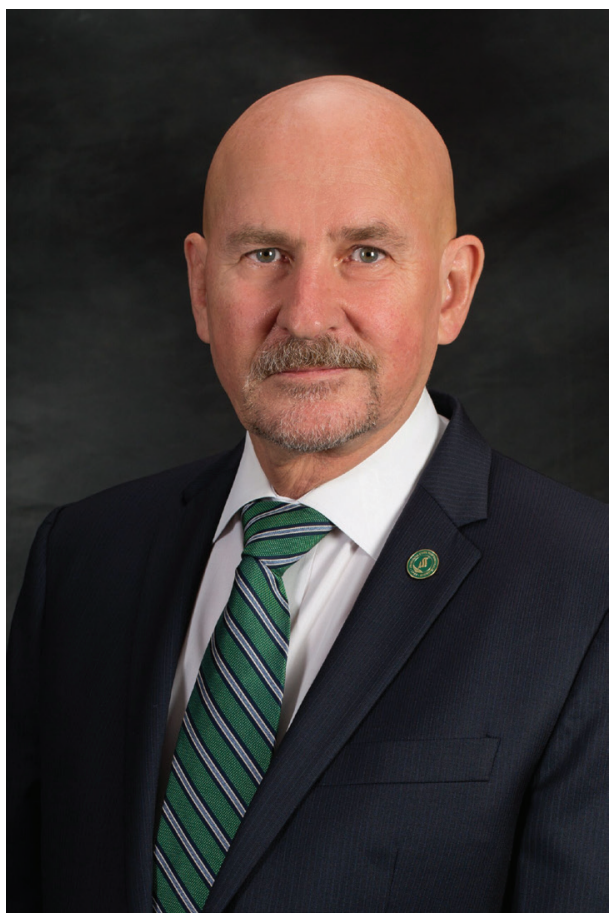

